\title{
mIOROSCOPY TODAY
}

SEPTEMBER I 996

ISSUE \#96-7

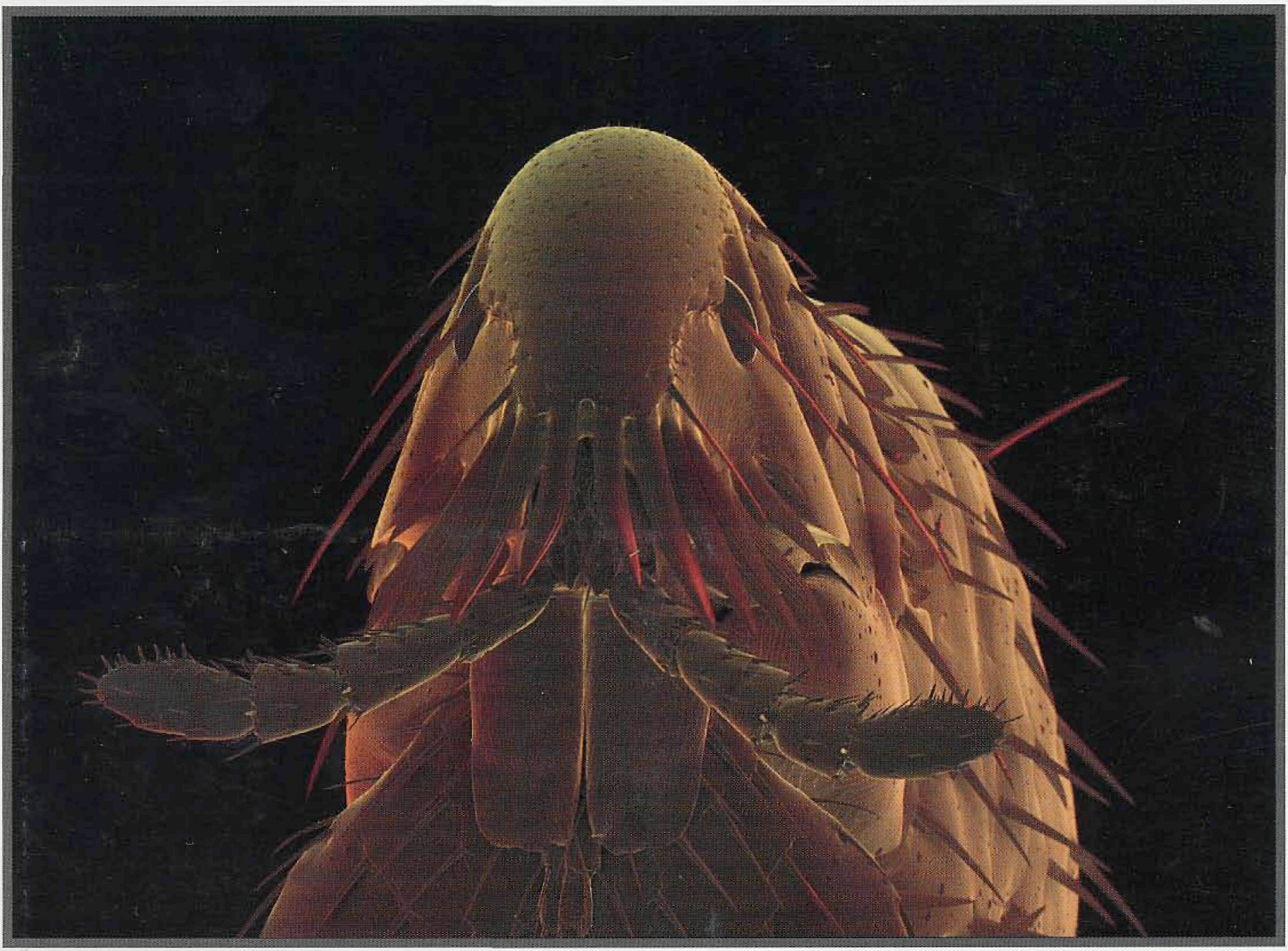



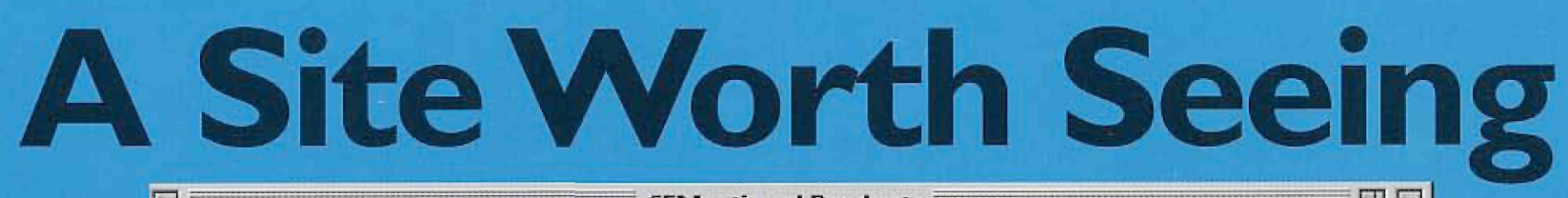

\begin{tabular}{|c|c|c|c|c|c|c|c|c|c|}
\hline 吐 & & & 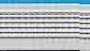 & EER & ation & Produ & ( & 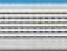 & 巴目 \\
\hline bo & $\Leftrightarrow$ & 哲 & B & 슬 & 40 & 圆 & 㩆 & 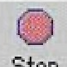 & \\
\hline Back & For ward & Home & Reload & Images & Open & Print & Find & Stop & \\
\hline
\end{tabular}

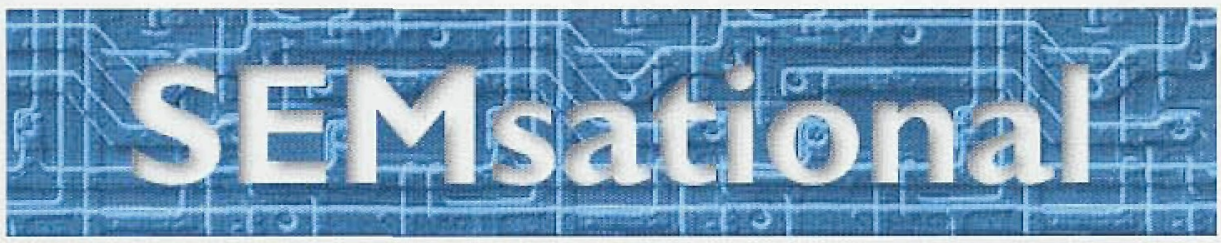

\section{Scanning Electron Microscopy with a Difference...}
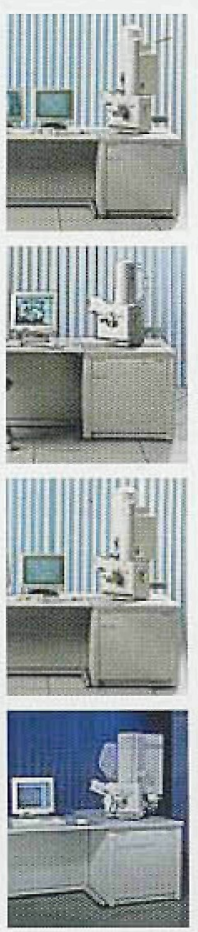

$X\llcorner 20$

Precision tilt eucentric $20 \mathrm{~mm} \times 20$ mmstage and a resolution down to 4 nm make the XL20 ideal for investigations and small samples.

XL30

Cham ber with many free ports a 50 $\times 50 \mathrm{~mm}$ tilt eucentric stage and $f u l$ system aut omation f or increased andical throughput, including EDX, MOX and EBSP.

\section{XL30FEG}

Same as the XL30 plusa

combination of high resolution and uriquely high and stable current for outstanding analytical perfomance

XL30ESEM-FEG

Featuring a patented gaseous secondary electron detector system, specimen exanination is by means of a FEG electron beam in an exceptionally high pressure environment, compatible with hydrated samples.
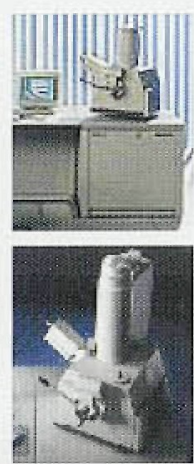

$X 140$

For large sample analysis, from IC waters to high-quality coated materials. XL40's features includea $150 \mathrm{~mm}$ motorized stage and $45^{\circ}$ tilting of large planar specimens.

X4OFEG

A hightech blending of the XL40 abovej with FEG resolution and stability make this instrument patticularlysuited for analytical applications

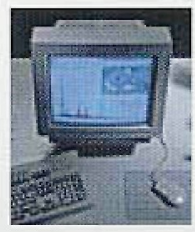

XL-Analytical

The custamized embed ding of EDX in any type $\mathrm{XL}$. Acommon software erwironiment and consistent user interface allows generation of highlevel automation packages.

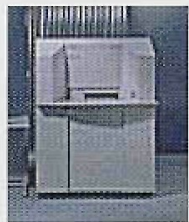

\section{XL50 FEG-DFT}

This advanced instrument combines a FEG electron source with a $200 x$

$200 \mathrm{~mm}, 5$-axis movement stage. Awerage stage acc uracyis within 1.5 microns across an 8 " wajer.

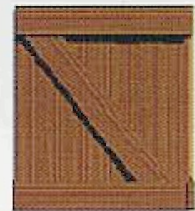

XL??

coming soon..
Philips XL Series SEMs reflect the perfect blend of elegant hardware and sophisticated software. System modularity and a choice of electron sources (tungsten; lanthanum hexaboride (LaB6), field emission (FEG)), enable a basic instrument to be configured to specific requirements. Menu-driven point-and-click mouse control contributes to unprecedented user friendliness. Take a look at the Philips XL Series SEMs. You'll find they're simply SEMsational!

\section{Let's make things better.}

Philips Electronic Instruments Co 85 McKee Drive, Mahwah, NJ 07430

Fax: $201-529$ 2252. Telephone: $201-5293800$ E-mail: marcom@eo,iephilips.n! Website-mowpeophilipscom
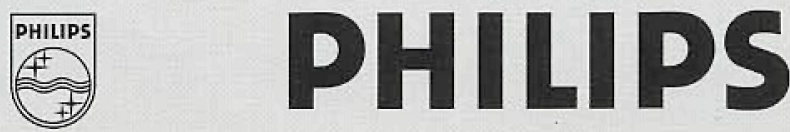